\title{
Interseismic crustal deformation in and around the Atotsugawa fault system, central Japan, detected by InSAR and GNSS
}

\author{
Youichiro Takada ${ }^{{ }^{*}} \mathbb{0}$, Takeshi Sagiya ${ }^{2}$ and Takuya Nishimura ${ }^{3}$
}

\begin{abstract}
The Atotsugawa fault system is one of the best-known active faults in Japan. However, revealing the interseismic velocity field in and around the Atotsugawa fault system with high spatial resolution is challenging because of dense vegetation, steep topography, and heavy snowfall in winter. To overcome these difficulties, we combined ALOS/ PALSAR data and GNSS data from our original stations in addition to the nationwide station network (GEONET). First, we removed the height-dependent phase change in each interferogram using a digital elevation model. Next, we removed the long-wavelength phase trend using the GNSS velocity field. Finally, we applied an InSAR time-series analysis, known as small baseline subset analysis (SBAS), to all the corrected interferograms. The resultant mean velocity field shows a remarkable phase gradient around the Atostugawa fault system. We found a sharp velocity gradient across the Ushikubi fault, a major strand of the Atotsugawa faults system, rather than the main trace of the Atotsugawa fault. Using InSAR, we found that the interseismic deformation inside the strain concentration zone is spatially heterogeneous and different from what we expect from the fault traces.
\end{abstract}

Keywords: InSAR, GNSS, Atotsugawa fault, Interseismic velocity

\section{Introduction}

It is well known that the interseismic strain rate of the Japan arc is non-uniform. For example, Sagiya et al. (2000) found a long-stretching strain concentration zone called the Niigata-Kobe tectonic zone (NKTZ) using GNSS data (Fig. 1). Meneses-Gutierrez and Sagiya (2016) further reported that inelastic strain processes are responsible for strain concentration along the NKTZ from GNSS-derived strain rates. Thus, interseismic deformation fields provide ways to understand the subsurface rheological heterogeneities beneath the Japan arc. To detect such a strain concentration at much higher spatial resolution, interferometric synthetic aperture radar (InSAR) analysis is a very powerful tool, which measures two-dimensional distributions of range changes between the surface and satellite (e.g., Massonnet et al. 1993).

\footnotetext{
*Correspondence: takaday@sci.hokudai.ac.jp

${ }^{1}$ Department of Earth and Planetary Sciences, Hokkaido University,

N10W8, Kita-ku, Sapporo 060-0810, Japan

Full list of author information is available at the end of the article
}

Recently, interseismic velocity fields become detectable using InSAR time-series analysis (Ferretti et al. 2001; Berardino et al. 2002; Schmidt and Bürgmann 2003) and/ or by stacking many interferograms (e.g., Fialko 2006; Hammond et al. 2012). In these previous studies, the satellite images acquired with short-wavelength radio wave (C- or X-band) were used for urban and/or semiarid areas. For densely forested areas, except for fault creeps, it remains challenging to detect long-wavelength interseismic deformation, although there have been some successful reports (e.g., Grandin et al. 2012; Huang et al. 2016). The Japan arc is characterized by dense vegetation, steep topography, and large snowfall, especially for the area along the Sea of Japan, factors that make interferograms less coherent. To overcome these difficulties, it is necessary to use L-band InSAR images. Furthermore, it is preferable to remove the long-wavelength noise included in the interferograms using GNSS velocities, because the dominant wavelength of such noise is similar to that of interseismic crustal deformation. Also high temporal resolution of GNSS is suitable for removing the effect 


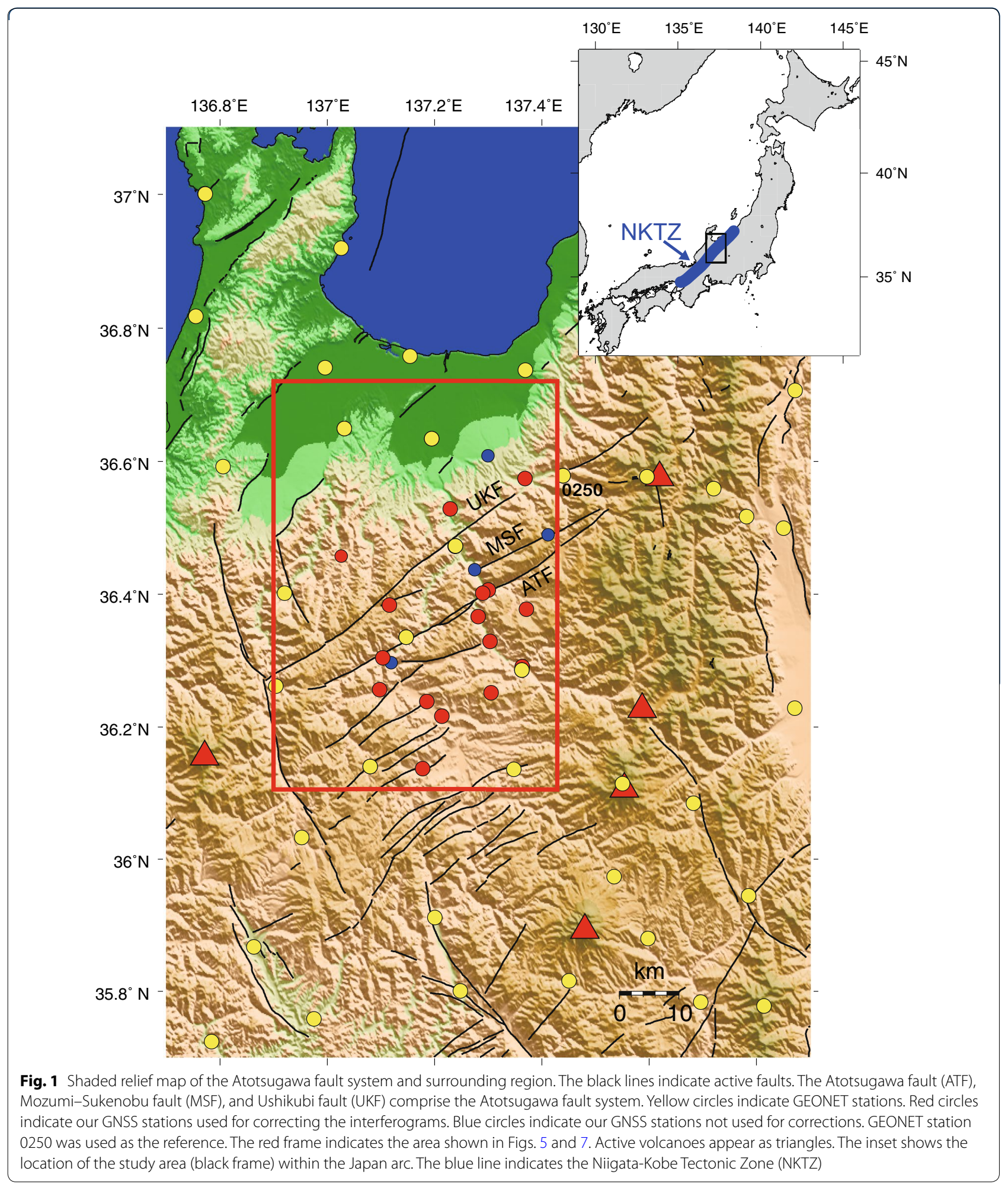

of atmospheric and/or ionospheric disturbances that change randomly in time.

The Atotsugawa fault system, central Japan, is a 70-kmlong active strike-slip fault system, which forms a part of the NKTZ (Fig. 1). The Atotsugawa fault system consists of three fault strands, the Ushikubi, Atotsugawa, and Mozumi-Sukenobu faults (Fig. 1). A dense GNSS network has been established (Fig. 1) and maintained in 
and around this fault system since 1997 by a university consortium comprised of Nagoya, Kyoto, Hokkaido, and Toyama universities. The continuous GNSS surveys in this network clarified the dextral motion of the Atotsugawa fault system at depth (Hirahara et al. 2003; Ohzono et al. 2011), which is consistent with WNW-ESE compressional stress field (e.g., Katsumata et al. 2010; Takada et al. 2016). In this study, we focus on the velocity field of this area before the 2011 Tohoku-Oki earthquake (Mw 9.0), with the goal of characterizing a more detailed interseismic velocity field in and around the Atotsugawa fault system by combining L-band InSAR and GNSS data.

\section{Methods}

We made interferograms of ALOS/PALSAR data acquired from the ascending orbit, path 410 frame 410420, with the GAMMA software suite (Wegmüller and Werner 1997). To remove topographic fringes, we used 10-m resolution digital elevation model (DEM) provided by the Geospatial Information Authority of Japan (GSI). We adopted the small baseline subset analysis (SBAS), a widely used algorithm of the InSAR time-series analysis (Berardino et al. 2002; Schmidt and Bürgmann 2003), to remove short-period phase disturbances mainly due to tropospheric and/or ionospheric effects. In the SBAS approach, we minimized the norm of the unknown velocity vector, where each component corresponds to a specific period, resulting in a time series of velocity field smoothed in time. Then, we defined the mean velocity as $\bar{v}=\frac{\sum_{i=1}^{n} v_{i} \Delta t_{i}}{\sum_{i=1}^{n} \Delta t_{i}}$, where $\Delta t_{i}$ and $v_{i}$ indicate the time interval and velocity of the $i$ th period, respectively. Figure 2 shows SAR data acquisition dates and interferometric

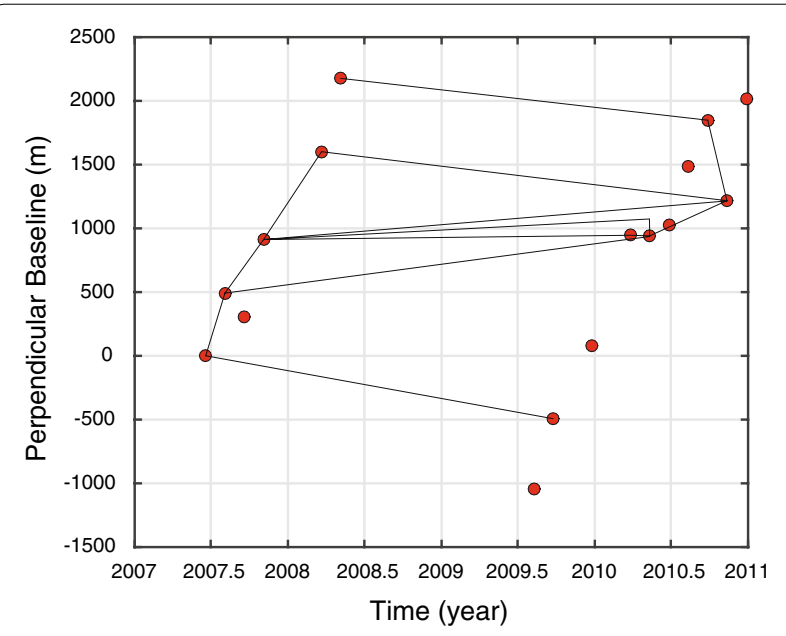

Fig. 2 SAR data acquisition dates (red circle) and interferometric pairs (black line) used for the time-series analysis. The details are provided in Table 1 pairs used for the time-series analysis, which are also listed in Table 1. We did not use interferograms with low coherence due to heavy snowfall. In addition, some interferograms affected by strong ionospheric disturbances were not used. We set the time span for each pair to as long as possible to increase the signal-to-noise ratio, which uses the advantages of the L-band SAR data. Figure 3 indicates the resultant mean velocity field, which is contaminated by the long-wavelength phase ramp due to the orbital estimation error and short-wavelength height-dependent phase change. These non-tectonic systematic errors must be corrected using the GNSS velocity field and DEM for each interferogram. To make these corrections effective, we focus on the central part of the Atotsugawa fault system indicated with the red frame in Fig. 1, which increases the GNSS station density and decreases the spatial variability in atmospheric stratification. The flowchart for all processing steps is illustrated in Fig. 4.

First, we removed the height-dependent phase change from each interferogram using the DEM. To make it precise, we temporarily estimated the bilinear phase ramp as well according to the following equation:

$$
\varphi_{i}=a+b x_{i}+c y_{i}+f h_{i}
$$

where $\varphi_{i}$ is the phase at the $i$ th pixel located at $\left(x_{i}, y_{i}\right)$ and $h_{i}$ is the altitude derived from the DEM. The parameters $a, b, c$, and $f$ are determined in a least squares manner. Then, we only subtracted the height-dependent term $f$ $h$ from each interferogram. As an example, the effect of this correction for an interferogram spanning 920 days is illustrated in Fig. 5a, b. The artificial displacements in the proximity of UKF, MSF, and ATF are markedly reduced.

Table 1 Interferometric pairs used for the time-series analysis

\begin{tabular}{llc}
\hline Master date & Slave date & Perpendicular baseline $(\mathbf{m})$ \\
\hline $2007 / 06 / 19$ & $2007 / 08 / 04$ & -492 \\
$2007 / 06 / 19$ & $2009 / 09 / 24$ & 491 \\
$2007 / 08 / 04$ & $2007 / 11 / 04$ & -420 \\
$2007 / 08 / 04$ & $2010 / 05 / 12$ & -453 \\
$2007 / 11 / 04$ & $2008 / 03 / 21$ & -689 \\
$2007 / 11 / 04$ & $2010 / 03 / 27$ & -34 \\
$2007 / 11 / 04$ & $2010 / 05 / 12$ & -33 \\
$2007 / 11 / 04$ & $2010 / 11 / 12$ & -304 \\
$2008 / 03 / 21$ & $2010 / 11 / 12$ & 385 \\
$2008 / 05 / 06$ & $2010 / 09 / 27$ & 328 \\
$2010 / 03 / 27$ & $2010 / 05 / 12$ & 1 \\
$2010 / 05 / 12$ & $2010 / 11 / 12$ & -271 \\
$2010 / 09 / 27$ & $2010 / 11 / 12$ & 632 \\
\hline
\end{tabular}




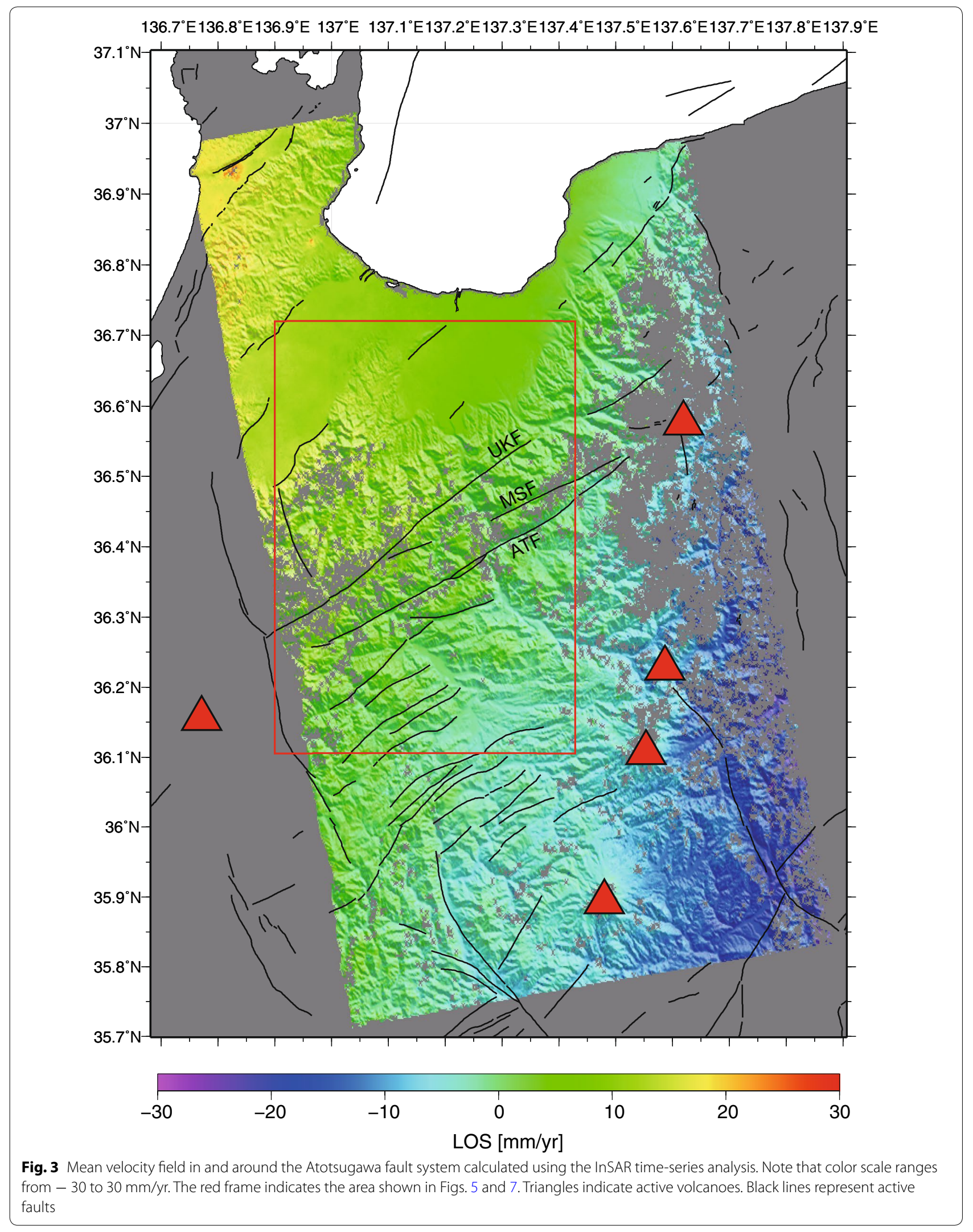




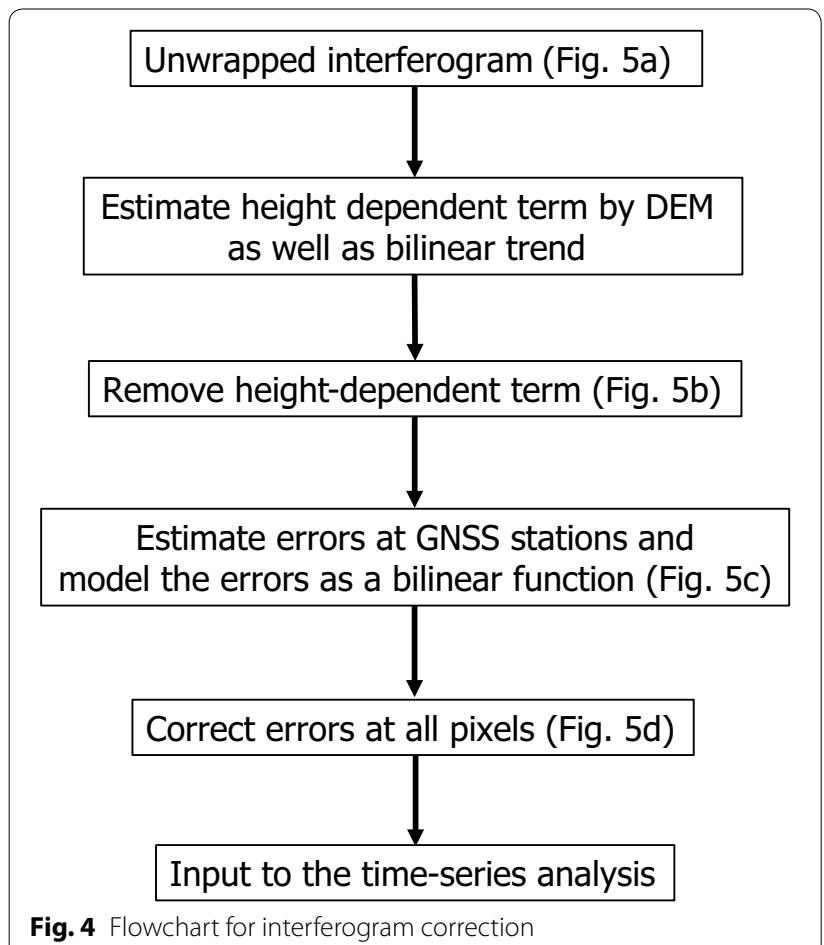

In addition, the river valleys are clearly visible in Fig. 5a (red broken lines) and are removed from Fig. 5b.

Next, by assuming the GNSS velocity field was correct and steady, we removed the long-wavelength phase ramp following the method proposed by Fukushima and Hooper (2011). We used GNSS velocities obtained by our own stations and GEONET (GNSS Earth Observation Network System) operated by GSI (Fig. 6). The GNSS velocities were obtained by modeling daily coordinates with a steady velocity plus annual and semiannual variations. Then, we multiplied the GNSS velocities by the interval of each interferogram to obtain the GNSS displacement necessary for the interferogram correction. We did not use the GNSS velocity data with large measurement errors in any component. We also did not use the GNSS velocity data showing very short wavelength deformation, because our purpose for using GNSS was to remove the long-wavelength trend. We set GEONET station 0250 (Figs. 1, 6) as a reference. The error at each GNSS station is written as

$$
d_{i}^{e r r}=d_{i}-d_{i}^{G P S}
$$

where $d_{i}$ is the line-of-sight (LOS) displacement obtained by InSAR, $d_{i}^{G P S}$ is the LOS displacement calculated from the GNSS data, and $d_{i}^{\text {err }}$ is the error defined at the GNSS stations (circles in Fig. 5c). Then, we modeled the longwavelength error included in the interferogram as

$$
d_{i}^{e r r}=s+p x_{i}+q y_{i}
$$

The parameters $p, q$, and $\mathrm{s}$ were determined using a least squares approach. Using Eq. 3, we estimated errors at arbitrary pixels as indicated in Fig. $5 \mathrm{c}$ and removed those errors from the interferogram. An example of a corrected interferogram is indicated in Fig. 5d, much flattened in comparison with the original interferogram (Fig. 5a). Finally, we used all the corrected interferograms for the time-series analysis and obtained the mean velocity field (Fig. 7).

\section{Results and discussion}

Figure 7 shows the mean velocity field after removing the height-dependent term and long-wavelength ramp using the GNSS data. To verify the effects of the correction, we compared Fig. 7 with the mean velocity field without any correction (Fig. 3). The LOS velocity in the focused area (red rectangle) approximately ranges from -10 to $20 \mathrm{~mm} /$ yr before the correction (Fig. 3), whereas it ranges from -5 to $5 \mathrm{~mm} / \mathrm{yr}$ after the correction (Fig. 7). Thus, such systematic errors are very large, and the phase correction by DEM and GNSS was clearly necessary before the time-series analysis.

In Fig. 7, we observe a remarkable change in the LOS velocity across the Ushikubi fault, a major strand of the Atotsugawa fault system (Fig. 1), rather than the main trace of the Atotsugawa fault. We set a profile perpendicular to the fault trace (line AA' in Fig. 7) and projected the LOS velocities within $1 \mathrm{~km}$ distance onto the profile (Fig. 8a). Taking a 30-point running average (blue line in Fig. 8a), we found that the LOS velocities change by about $3 \mathrm{~mm} / \mathrm{yr}$ across the Ushikubi fault. The width of the large gradient zone is about $3 \mathrm{~km}$. The increase in the LOS velocity is consistent with the dextral motion along the fault; the northern side moves away from the satellite and the southern side moves toward it. We further compared the LOS velocity field and local topography (Fig. 8b) and confirmed that they are poorly correlated.

Judging from smoothness of the one-dimensional profile (Fig. 8a), the velocity change across the Ushikubi fault does not indicate fault creep at the surface. The locking depth beneath the Ushikubi fault would be shallower than that of the Atotsugawa fault, which may cause strain concentration along the Ushikubi fault. Previous studies have reported dextral motion of the Atotsugawa fault system from GNSS data (Hirahara et al. 2003; Ohzono et al. 2011), but they focused on the movement of the "Atotsugawa fault system," not its interior. With much higher spatial resolution of InSAR, we revealed the internal structure of the Atotsugawa fault system and the role of the Ushikubi fault. To evaluate the compatibility between the GNSS velocity data and corrected mean velocity, we calculated LOS velocities from the GNSS data and projected those onto the same profile as in Fig. 8 (Fig. 9). We 


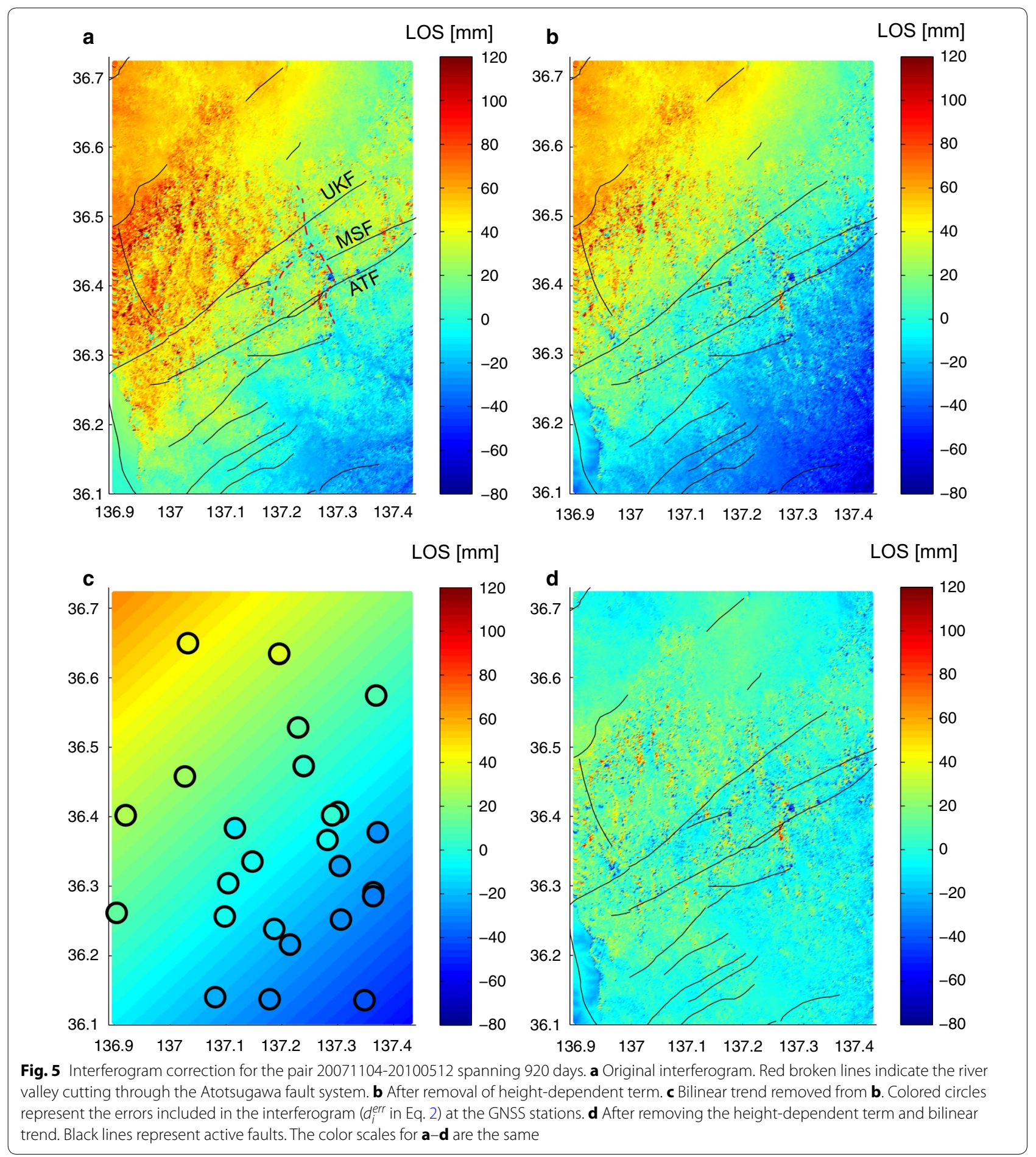



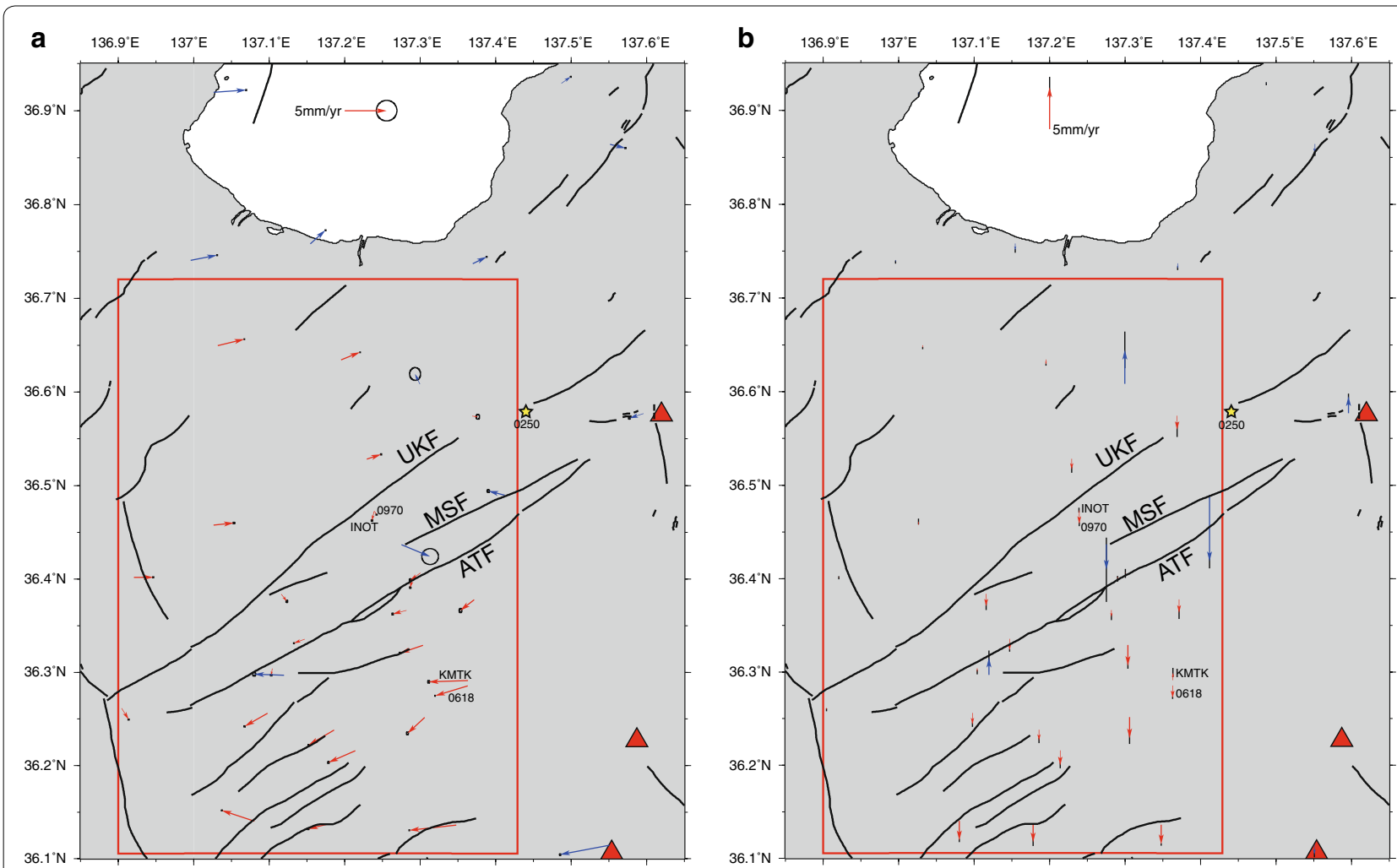

Fig. 6 GNSS velocity field. a Horizontal components and $\mathbf{b}$ vertical component with respect to 0250 (star). Red arrows indicate the velocity vectors used for the correction of the interferograms. Blue arrows are those not used for the correction. For horizontal components, the ellipse at the tip of each vector represents the $95 \%$ confidence interval. For vertical components, the error bar at the tip of each vector represents the $95 \%$ confidence interval. The red frame indicates the area shown in Figs. 5 and 7. Triangles indicate active volcanoes. Black lines represent active faults

found that the spatial gradient in the GNSS-derived LOS velocity has a peak between the Atotsugawa and Ushikubi faults (Fig. 9b), unlike in Fig. 8, which means that both of the velocities obtained from GNSS and InSAR are not perfectly noiseless. Thus, we cannot derive clear conclusions from this direct comparison between GNSS and InSAR. However, we may say that the velocity gradient does not have its maximum across the Atotsugawa fault. This tendency can be seen in figures from previous studies (Hirahara et al. 2003; Ohzono et al. 2011), although it was not specifically described. In Fig. 9b, two university stations KMTK and INOT are located very close (623 and $41 \mathrm{~m}$ ) to GEONET stations 0618 and 0970, respectively. As the GEONET stations are more firmly constructed than the university stations, we conclude that KMTK and INOT include non-tectonic displacements (site effects), which leads to the large deviations from the overall trend (Fig. 9b).
We cannot exclude the possibility that the mean velocity field shown in Fig. 7 still includes a certain amount of systematic noise mainly due to atmospheric disturbances. Figure 10 illustrates the time series of cumulative displacements at two locations $\mathrm{X}$ and $\mathrm{Y}$ in Fig. 7. As shown, the cumulative displacements do not increase proportionally with time, which means that the velocity field is not smooth enough in time. Also the clear velocity gradient across the Ushikubi fault is restricted to the central part of the fault (Fig. 7). As for the western part of the Ushikubi fault, the low coherence prevents us from providing definitive conclusions. Therefore, the large displacement gradient across the Ushikubi fault that we found is possibly caused by tectonic processes, although we need more image acquisitions and technical improvements to reduce the effect of systematic noise. The current activity of the Ushikubi fault, and its geological slip rate, should be clarified in the future. 


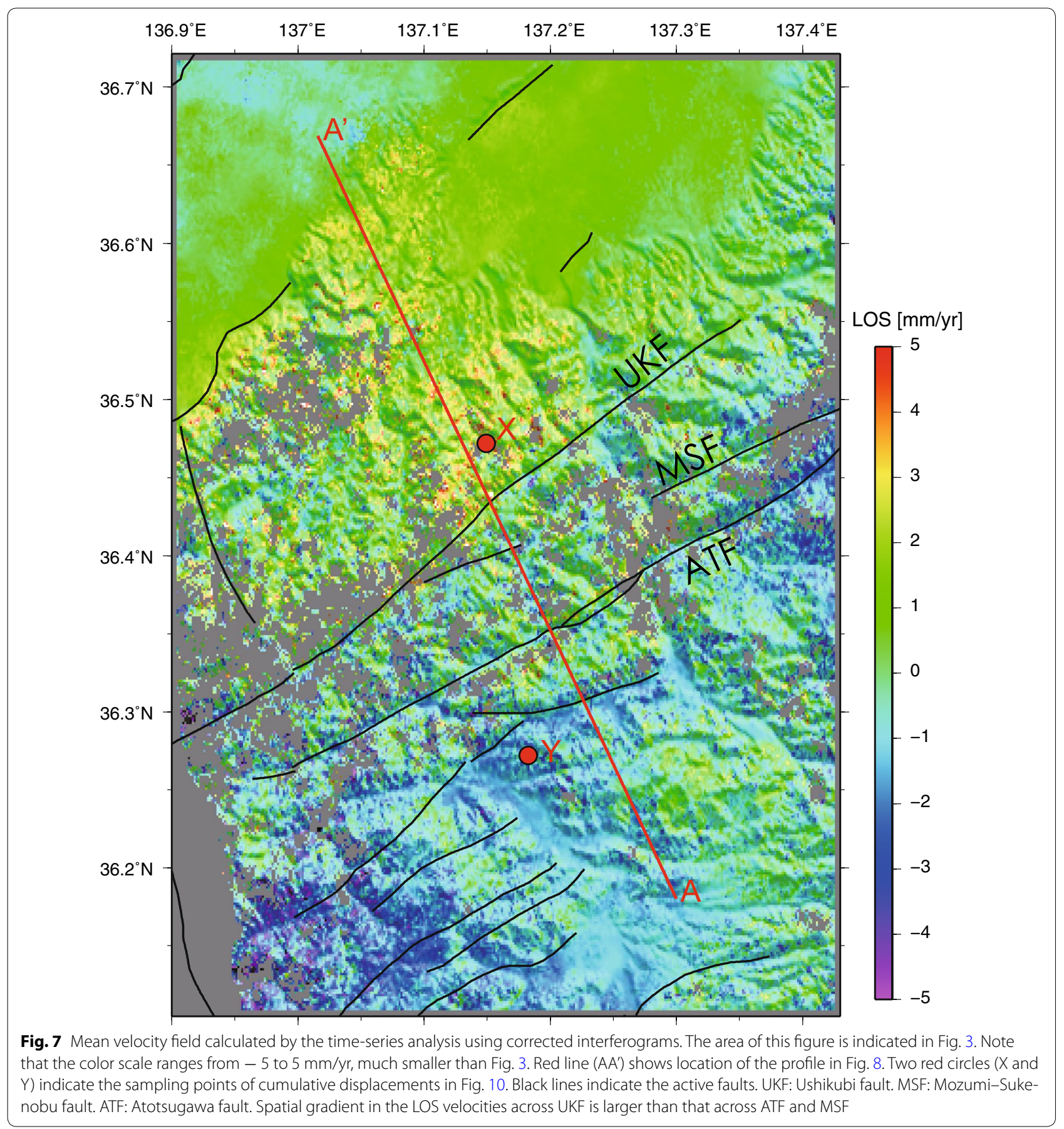



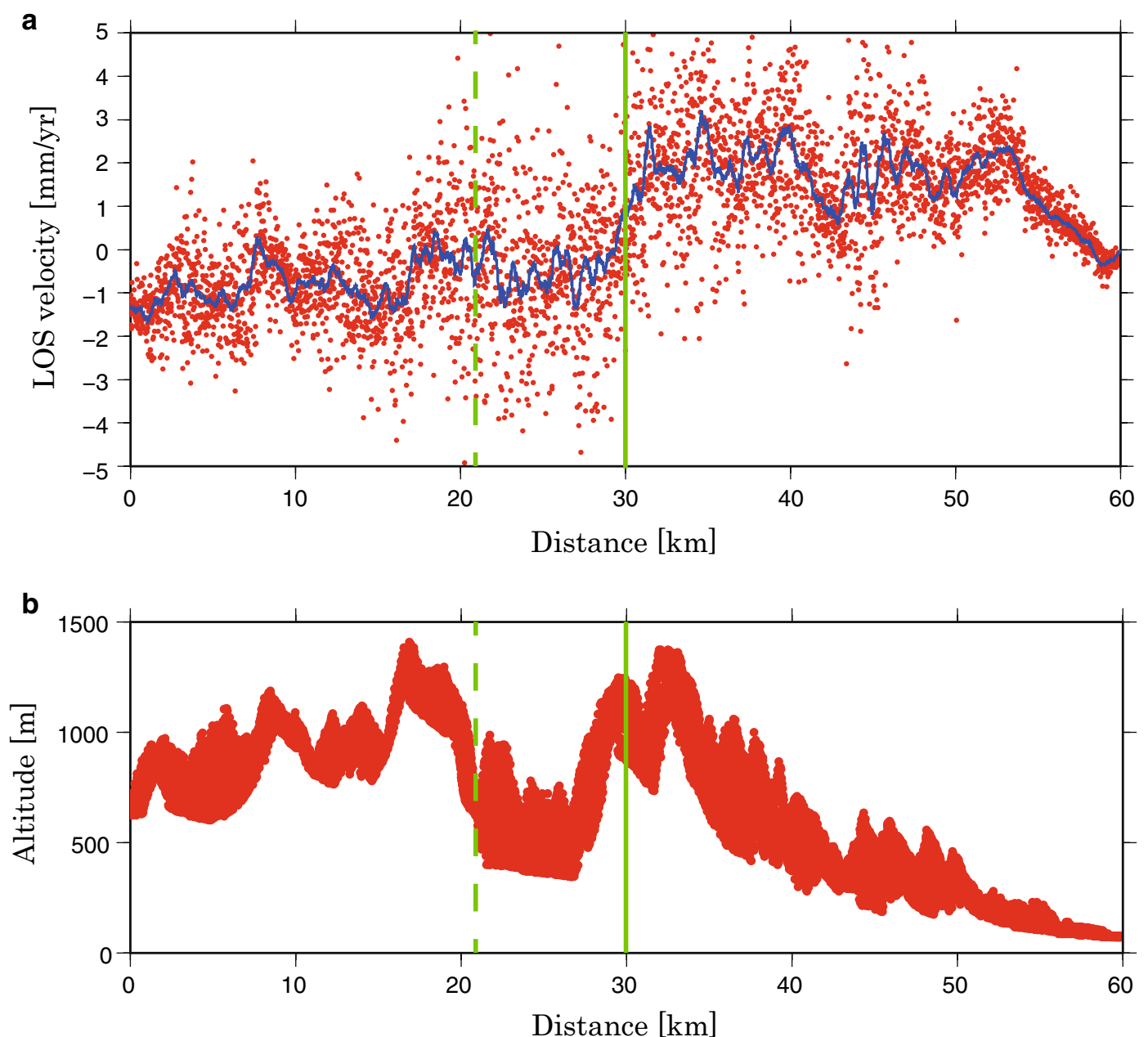

Fig. 8 Profiles of $\mathbf{a}$ LOS velocities and $\mathbf{b}$ altitudes along AA' in Fig. 7. Blue line indicates 30 points running average. Green solid and broken lines at $\sim 30 \mathrm{~km}$ and $\sim 21 \mathrm{~km}$ along the horizontal axis indicate the location of the Ushikubi and Atotsugawa faults, respectively

\section{Conclusions}

We presented a high-resolution interseismic velocity field in and around the Atotsugawa fault system, central Japan, using both GNSS and InSAR. We removed the height-dependent term and long-wavelength phase trend in each interferogram using DEM and GNSS data, respectively. Finally, we applied an InSAR timeseries analysis to the corrected interferograms. The resultant LOS velocity field is consistent with dextral fault motion, and it revealed a large velocity gradient across the Ushikubi fault, a major strand of the Atotsugawa fault system. The possibility remains that this sharp gradient is an artifact caused by atmospheric disturbance. However, we can conclude that the velocity gradient does not have its maximum across the Atotsugawa fault. In summary, high spatial resolution SAR 

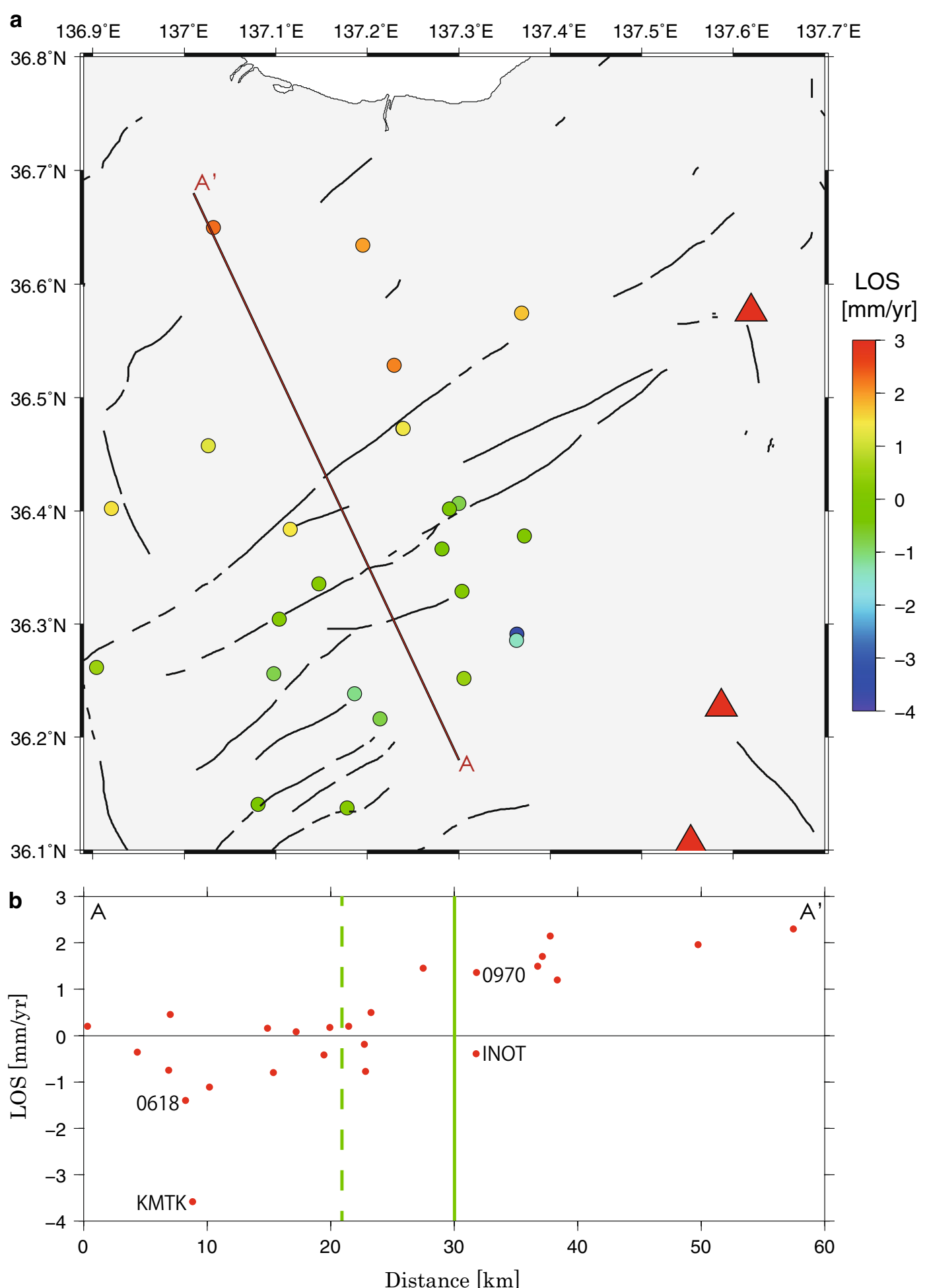

Fig. 9 a LOS velocities calculated from GNSS data. Red triangles indicate active volcanoes. b One-dimensional profile of the GNSS-derived LOS velocities. The profile is indicated by the red line (AA') in $\mathbf{a}$, which is the same as $A A^{\prime}$ in Fig. 7. Green solid and broken lines at $\sim 30$ and $\sim 21 \mathrm{~km}$ along the horizontal axis indicate the locations of the Ushikubi and Atotsugawa faults, respectively 

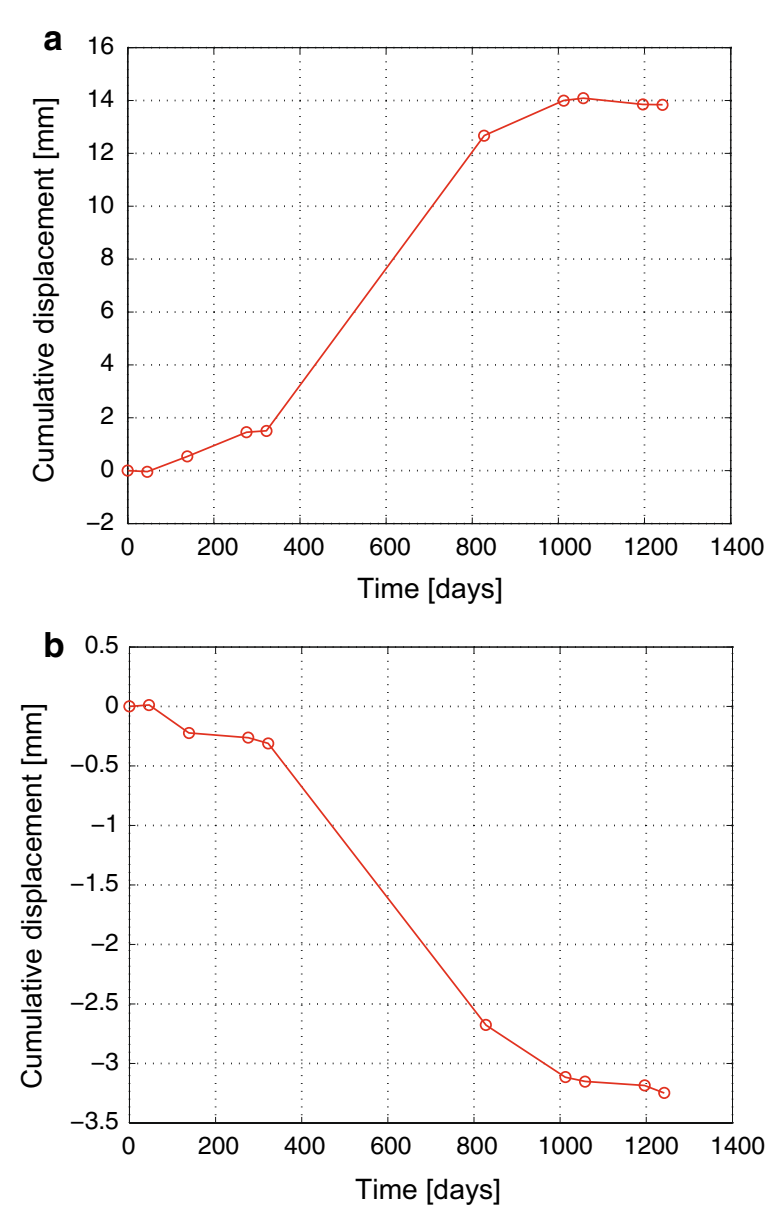

Fig. 10 Time-series plot of cumulative displacements. The cumulative displacements at points $\mathrm{X}$ and $\mathrm{Y}$ in Fig. 7 are plotted in $\mathbf{a}$ and b, respectively. The red circle corresponds to the date of SAR data acquisition

images combined with a dense GNSS network enable us to examine the internal structure of the fault system even in the low coherence area due to dense vegetation, steep topography, and heavy winter snowfall.

\section{Authors' contributions}

YT conducted the SAR processing and GNSS observations and drafted the manuscript. TS and TN conducted the GNSS observation and analysis. All authors read and approved the final manuscript.

\section{Author details}

1 Department of Earth and Planetary Sciences, Hokkaido University, N10W8, Kita-ku, Sapporo 060-0810, Japan. ${ }^{2}$ Disaster Mitigation Research Center, Nagoya University, Furo-cho, Chikusa-ku, Nagoya 464-8601, Japan. ${ }^{3}$ Research Center for Earthquake Prediction, Disaster Prevention Research Institute, Kyoto University, Gokasho, Uji, Kyoto 611-0011, Japan.

\section{Acknowledgements}

PALSAR Level 1.0 data were provided from the PIXEL (PALSAR Interferometry Consortium to Study our Evolving Land surface) group under a cooperative research contract between JAXA and ERI, University of Tokyo. PALSAR data were also provided from JAXA under ALOS2-PI project. The ownership of PALSAR data belongs to JAXA and METI, Japan. GEONET data and DEM were provided by GSI, Japan. Parts of the figures were created by Generic Mapping Tools (Wessel and Smith 1998). Comments by Yosuke Aoki and an anonymous reviewer were helpful in improving the manuscript.

\section{Competing interests}

The authors declare that they have no competing interests.

\section{Ethics approval and consent to participate}

Not applicable.

\section{Availability of data and materials}

Velocity field estimated by InSAR is available by email request to the corresponding author.

\section{Funding}

This study was supported by MEXT KAKENHI Grant Nos. 26400454, 26109003, and 26109007 to YT, TS, and TN.

\section{Publisher's Note}

Springer Nature remains neutral with regard to jurisdictional claims in published maps and institutional affiliations.

Received: 31 March 2017 Accepted: 7 February 2018

Published online: 16 February 2018

\section{References}

Berardino P, Fornaro G, Lanari R, Sansosti E (2002) A new algorithm for surface deformation monitoring based on small baseline differential SAR interferograms. IEEE Trans Geosci Remote Sens 40(11):2375-2383

Ferretti A, Prati C, Rocca F (2001) Permanent scatterers in SAR interferometry. IEEE Trans Geosci Remote Sens 39(1):8-20

Fialko Y (2006) Interseismic strain accumulation and the earthquake potential on the southern San Andreas fault system. Nature 441:968-971

Fukushima Y, Hooper A (2011) Crustal deformation after 2004 NiigatakenChuetsu Earthquake, central Japan, investigated by persistent scatterer interferometry. J Geod Soc Jpn 57:195-214 (In Japanese with English abstract)

Grandin R, Doin MP, Bollinger L, Pinel-Puysségur B, Ducret G, Jolivet R, Sapkota SN (2012) Long-term growth of the Himalaya inferred from interseismic InSAR measurement. Geology 40:1059-1062

Hammond WC, Blewitt G, Li Z, Plag HP, Kreemer C (2012) Contemporary uplift of the Sierra Nevada, western United States, from GPS and InSAR measurements. Geology 40:667-670

Hirahara K, Ooi Y, Ando M, Hoso Y, Wada Y, Ohkura T (2003) Dense GPS Array observations across the Atotsugawa fault, central Japan. Geophys Res Lett 30:8012. https://doi.org/10.1029/2002GL015035

Huang MH, Bürgmann R, Hu JC (2016) Fifteen years of surface deformation in Western Taiwan: insight from SAR interferometry. Tectonophysics 692:252-264

Katsumata K, Kosuga M, Katao H, The Japanese University Group of the Joint Seismic Observations at NKTZ (2010) Focal mechanisms and stress field in the Atotsugawa fault area, central Honshu, Japan. Earth Planets Space 62:367-380

Massonnet D, Rossi M, Carmona C, Adragna F, Peltzer G, Feigl K, Rabaute T (1993) The displacement field of the Landers earthquake mapped by radar interferometry. Nature 364:138-142

Meneses-Gutierrez A, Sagiya T (2016) Persistent inelastic deformation in central Japan revealed by GPS observation before and after the Tohoku-oki earthquake. Earth Planet Sci Lett 450:366-371

Ohzono M, Sagiya T, Hirahara K, Hashimoto M, Takeuchi A, Hoso Y, Wada Y, Onoue K, Ohya F, Doke R (2011) Strain accumulation process around the Atotsugawa fault system in the Niigata-Kobe Tectonic Zone, central Japan. Geophys J Int 184:977-990

Sagiya T, Miyazaki S, Tada T (2000) Continuous GPS array and present-day crustal deformation of Japan. PAGEOPH 157:2303-2322

Schmidt DA, Bürgmann R (2003) Time-dependent land uplift and subsidence in the Santa Clara valley, California, from a large interferometric 
synthetic aperture radar data set. J Geophys Res 108:2416. https://doi. org/10.1029/2002JB002267

Takada Y, Katsumata K, Katao H, Kosuga M, lio Y, Sagiya T, The Japanese University Group of the Joint Seismic Observations at the Niigata-Kobe Tectonic Zone (2016) Stress accumulation process in and around the Atotsugawa fault, central Japan, estimated from focal mechanism analysis. Tectonophysics 682:134-146
Wegmüller U, Werner C (1997) Gamma SAR processor and interferometry software. In: Proceedings of the 3rd ERS symposium European space agency, Spec Publ, pp 1687-1692

Wessel P, Smith WHF (1998) New, improved version of generic mapping tools released. EOS Trans Am Geophys Union 79:579. https://doi. org/10.1029/98EO00426

\section{Submit your manuscript to a SpringerOpen ${ }^{\circ}$ journal and benefit from:}

- Convenient online submission

- Rigorous peer review

- Open access: articles freely available online

- High visibility within the field

- Retaining the copyright to your article

Submit your next manuscript at $\boldsymbol{\nabla}$ springeropen.com 